\title{
DIAGNOSTIC METHODS OF CANINE TRANSMISSIBLE VENEREAL SARCOMA
}

\author{
Iryna Pashkevych \\ Department of Parasitology \& Tropical veterinary \\ National University of Life and Environmental Sciences of Ukraine \\ 15 Geroiv Oborony str., Kyiv, Ukraine, 03041 \\ Pashk_Ira@ukr.net \\ Volodymyr Stybel \\ Department of Parasitology \& Ichthyopathology \\ Stepan Gzhytskyi National University of Veterinary Medicine and Biotechnologies Lviv \\ 50 Pekarska str., Kyiv, Ukraine, 79010 \\ vstybel@ukr.net \\ Natalia Soroka \\ Department of Parasitology \& Tropical veterinary \\ National University of Life and Environmental Sciences of Ukraine \\ 15 Geroiv Oborony str., Kyiv, Ukraine, 03041 \\ 5278823@ukr.net
}

\begin{abstract}
Modern diagnostic of oncological diseases, along with classical clinical and morphological methods, provides for the mandatory use of instrumental immunological, immunocytochemical and molecular genetic research methods. The main tasks of such a complex of diagnostic measures are aimed at monitoring oncological diseases at all stages of the diagnostic and treatment process, namely: the detection of a tumor at early stages of its development and the study of changes in metabolic processes in the body under the influence of neoplasms, morphological confirmation of the diagnosis, identification of histostructure and histogenesis of the tumor, determination the degree of its malignancy, detection of metastatic lesion (regional and distant lymph nodes and other organs) or assessment of the risk of its occurrence. It is well know that the early stages of oncological diseases are difficult to diagnose. At the same time, early detection of the disease can save or significantly extend the life of the patient. In such cases, the determination in the blood of specific substances, which are produced by tumors of the respective organs, the so-called oncomarkers, has been successfully used by world medical practice for more than 40 years to establish the affected organ. In combination with instrumental methods (ultrasound, endoscopy, X-ray), diagnostic efficiency is sharply increasing. Successful treatment of malignant tumors is possible under the conditions of their early detection and thorough histological diagnosis. Almost $50 \%$ of the total number of oncologically diseased dogs has tumorous processes in the tissues of their genital organs, aggressiveness and metastasis, which often leads to lethal consequences, even after radical interventions. The aim of our research was to study the histological, cytological and immunohistochemical characteristics of transmissible venereal sarcoma. It has be en established that histologically, the tumor belongs to the low-differentiated round-cellular sarcoma of the alveolar type. Typical is tumor infiltration by lymphocytes, plasma cells, macrophages. Tumor cells are characterized by the presence of a mesenchymal marker vimentine. A positive local reaction on myogenin, cytokeratin and negative on CD31, CD34, S-100 protein and desmin was observed.
\end{abstract}

Keywords: transmissible venereal sarcoma; histological; cytological and immunohistochemical studies.

\section{Introduction}

Improvement and development of new diagnostic and treatment methods of tumors in the animals genital area is one of the urgent problems of veterinary medicine [1]. The study of spontaneous neoplasms in dogs is an important task of comparative oncology, since these animals directly interact with humans and are exposed to the same environmental factors [2].

The main veterinary-medical issues of oncology are the establishment of a possible connection between tumors of animals and humans [3]. This became especially evident when the ability of many oncogenic viruses to overcome interspecific barriers was proven [4]. 
Undoubtedly, one of the fundamental problems is the use of animals as biological models for the study of some neoplastic human diseases, including the evaluation of the effectiveness of new antitumor drugs and various methods of tumors treatment [5].

Nowadays, due to the appearance of a large number of domestic and homeless small unproductive animals of various breeds of dogs, the problem of cancer diseases of their genitals acquire a special significance due to the poorly studied pathogenesis and the lack of criteria for early diagnosis. In this case, the most common in this group of diseases is a transmissible venereal sarcoma [6].

Despite the existing researches in this area, the etiological factors contributing to the development of the disease remain poorly understood. In connection with this, difficulties arise in the early diagnosis, treatment and prevention of this disease. Canine transmissible venereal sarcoma usually occurs more often than it is diagnosed, since objective clinical manifestations (bleeding, ulcers, changes in the anatomical structure of the genital organs) are detected only at the stage when the tumor affects the main part of the genital organs $[7,8]$.

Based on the foregoing, there is a need to develop an effective system of scientifically sound approach to the issues of diagnosis, treatment and prevention of transmissible venereal sarcoma [9].

It is known $[10,11]$ that $42 \%$ of malignant tumors are mesenchymal origin tumors, $32 \%$ are tumors of ectodermal origin, $22 \%$ are mesodermal tumors. And this applies to both tumors from embryonic cells and tumors that develop from mature cells.

Numerous studies of the peculiarities of «chemism» of malignant neoplasms have made it possible to establish that in tumors changes almost all links in the metabolism [12]. As the tumors develop, more and more features of the exchange of cancer cells, which are associated with high protein synthesis and delayed decay of proteins in the tumor, are increasingly manifested [13]. With the growth of tumor, it changes the composition of nucleic acids, the activity of enzymes, the degree of hydration of tumor cells, the concentration of mineral elements, lipids, etc. [14].

The «chemism» of cancer cell was considered comprehensively, but regardless of what the theoretical background was, biochemical studies quickly came up against a serious problem - the heterogeneity of cancer tissue. Heterogeneity is associated not only with the uneven distribution of different histological elements (connective tissue, parenchyma) in different parts of the tumor, but also with the chemical heterogeneity of the cancer cells itself, which received in the work of T. Kasperson the name «chemical variability» $[15,16]$.

\section{Aim of research}

The aim of the study was to improve the histochemical and immunohistochemical methods of diagnosis of canine transmissible venereal sarcoma.

\section{Materials and Methods}

For histological studies, the material (whole or part of the tumor) was taken together with the capsule and the part of the surrounding healthy tissue and placed in a separate dish with $10 \%$ solution of neutral buffered formalin [17]. After fixation, the batch was poured into paraffin, $5 \mathrm{~mm}$ thick histological sections were made and stained with hematoxylin Caracas and eosin. For the study the histochemical structure of the tumor, Brash reaction, alkaline phosphatase, PAS-reaction, and Azan staining were used [18, 19].

Material for cytological researches was obtained after the rapid removal of transmissible venereal sarcoma. Secimen were stained according to Papenheim and Papanikolaou [20].

For tumor cell immunohistochemical studies, markers were used: vimentin, cytokeratin, myogenin, CD34, CD31, S-100 protein and desmin [21].

\section{Results}

At cytological research, tumor cells are round or oval, monomorphic (Fig. 1). The nuclei are large, oval or round, eccentrically located, with a non-uniform, deep structure of chromatin. The basophilic cytoplasm, often with signs of vacuolar dystrophy, is large, light blue. The cells are placed close to each other, but do not form specific structures. 


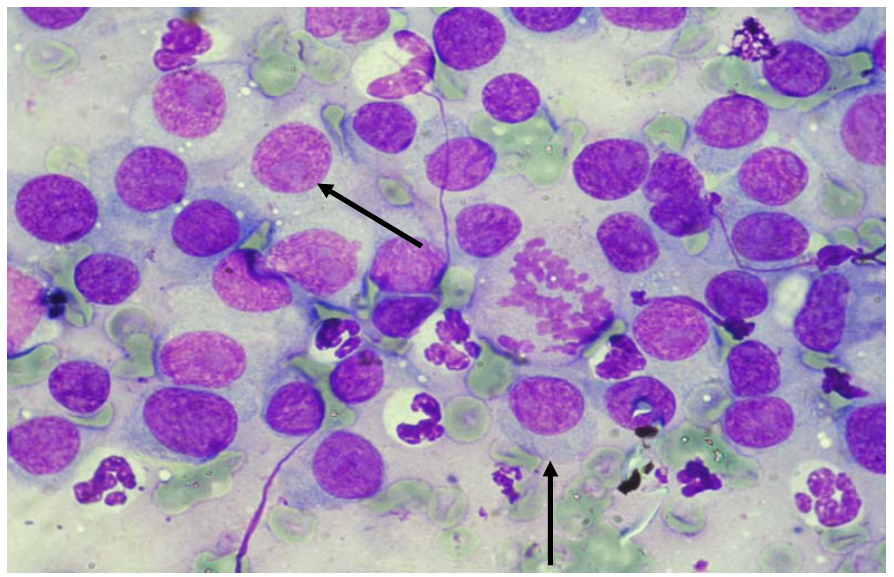

Fig. 1. Transmissible venereal sarcoma cells of spontaneous origin from a 3-year-old dog, stained according to Papenheim, amplification $\times 1000$

Tumor parenchyma is represented by circular cellular elements of mesenchymal genesis. The nuclei of tumor cells are volumetric, rich in condensed heterochromatin. The bright chromatin areas in the nucleus are small. The form of the nucleus of tumor cells is usually round or oval. Sometimes there are nuclei of irregular shape. In the nucleus, one nucleus is visualized. The nucleus is located in the center of the tumor cell, it occupies almost the whole it's volume. The cytoplasm is narrow, colored with eosin in pale pink color. In some tumor cells, the cytoplasm has a basophilic (pale blue) hue. Atypical tumor cells are moderately affected.

One of the sites visualizes the mitoses of tumor cells. The tumor is poor, represented by single fibroblasts (their nucleus is elongated, the cytoplasm is narrow, with a basophilic tint) and thin collagen fibers (Fig. 2).

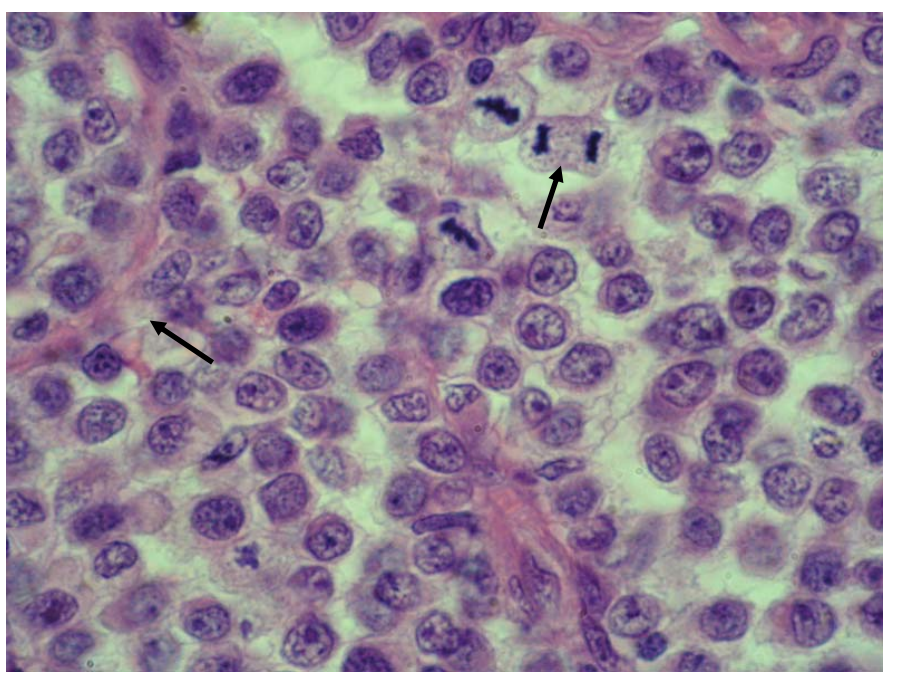

Fig. 2. Tissue of transmissible venereal sarcoma of spontaneous origin from a 4-year-old dog (staining with hematoxylin of Karachi and eosin, amplification $\times 1000$ )

In the stroma of the tumor, newly formed vessels are visualized. The endothelium is somewhat swollen, connective tissue elements of the walls of the vessels are embroidered. Connective tissue around the vessel is abundantly infiltrated with histiocytes and lymphocytes. In the lumen of the vessel are the remains of hemolyzed erythrocytes and lymphocytes. In addition, in the stromal tumor, isolated fibroblasts and small collagen fibers are visualized. The destruction of the walls of the vessels is not marked.

Tumor cells are freely located, between them there are gaps (Fig. 3). 


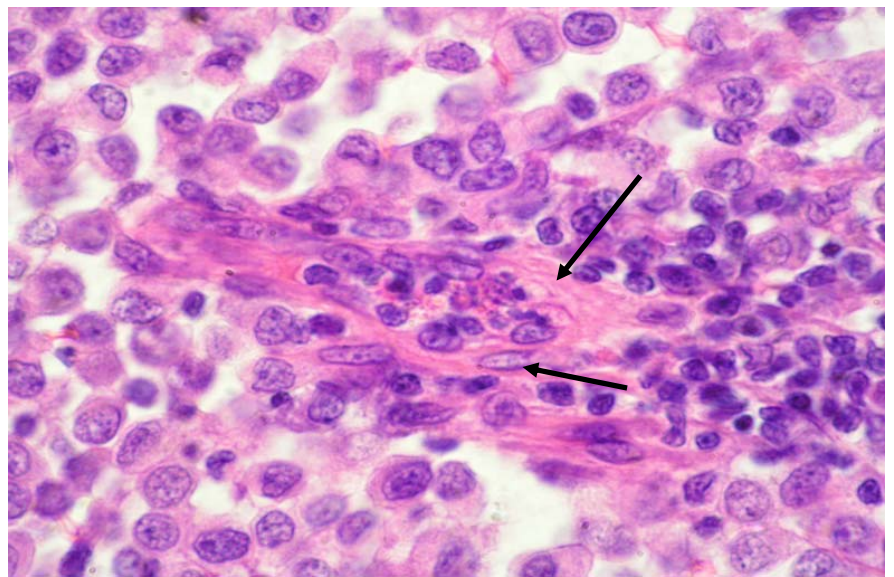

Fig. 3. Newly formed vessels in the stroma of the tumor. Tissue of a transmissible venereal sarcoma of spontaneous origin from a 5-years-old dog (staining with hematoxylin of Karachi and eosin, amplification $\times 1000$ )

The nuclei of tumor cells have round, oval, sometimes irregular form. The cytoplasm of the tumor cells is a small amount of the cell, colored in light pink color, sometimes with a basophilic tinge. Atypical tumor cells are moderate.

Tumor cells of the mesenchymal genus of round form, located in the form of a small focus, surrounded by connective tissue stroma. Tumor cells contain a bulky rounded nucleus, with lumps of condensed basophilic heterochromatin. The cytoplasm of the tumor cells is narrow, slightly eosinophilic (light pink), with a slightly basophilic (light-purple) tint. In some tumor cells, the cytoplasm is enlightened. In the stromal capillaries of the tumor, erythrocytes, lymphocytes and segmental neutrophil granulocytes are visualized. At the periphery of the tumor focus, the elongated fibroblasts nuclei and thin collagen fibers that surround the tumor focus are visualized. On the periphery of the tumor focus are also placed tumor cells, and in the stroma are visualized single lymphocytes, erythrocytes, neutrophilic granulocytes, fibroblasts (Fig. 4).

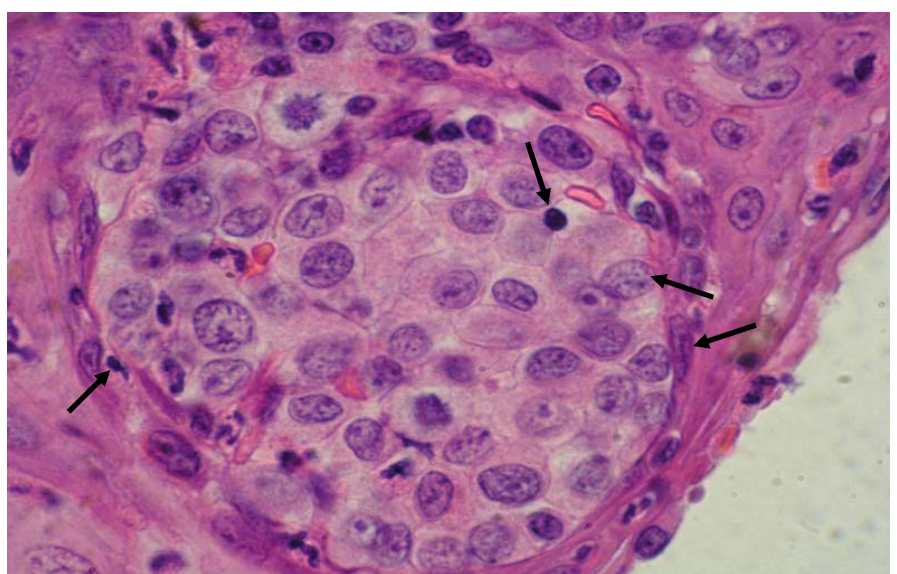

Fig. 4. Focus tumor surrounded by connective tissue stroma. Tissue of a transmissible venereal sarcoma of spontaneous origin from a 1.5-years-old dog (staining with hematoxylin Karachi and eosin, amplification $\times 1000$ )

Around the tumor cells is a significant amount of plasma cells. Plasmonocyte cytoplasm is intensely pyrononinophilic (red color), due to the presence of a significant amount of ribosomal RNA in it, the nucleus is located eccentrically, light green color, and the lumps of condensed heterochromatin are arranged in the form of spokes of the wheel.

The nucleus of tumor cells is round, oval, less elongated, its main area is colored in the light or intensely green color (due to a significant amount of DNA). In addition, in the nucleus of tumor 
cells, a clearly visible nucleolus is painted with pyronin in red color, due to the presence of a significant amount of RNA in it.

The cytoplasm of the tumor cells is colored in light pink color, indicating that there is a moderate amount of RNA in it (Fig. 5).

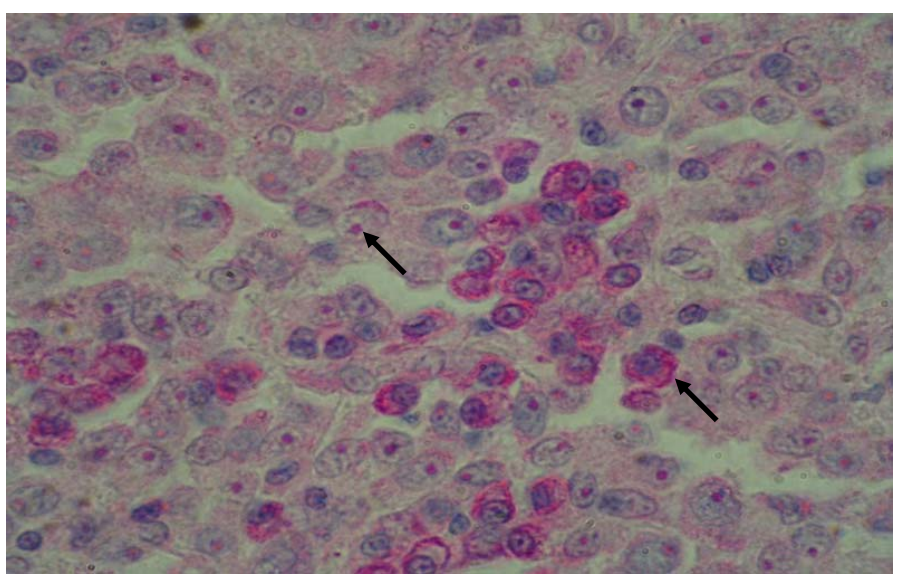

Fig. 5. Plasma citrate infiltration of tumor stroma. Tissue of transmissible venereal sarcoma of spontaneous origin from a 3-year-old dog (staining of methylene green and pyronin G by Brashe, amplification $\times 1000$ )

The newly formed vessel of the tumor stroma is enlarged, filled with erythrocytes, which are unevenly swollen, placed in several rows. Most of the erythrocytes are deformed, some of them are glued (stasis), some are hemolysed, the boundaries between erythrocytes are poorly visualized. The destruction of the vessel wall was not recorded. No tumor cells were found in the lumen of the vessels.

In the stroma, the elongated fibroblasts nuclei are located. The cytoplasm of fibroblasts is narrow, small fine collagen fibers leave from it, which were painted by water blue in a light blue color and form the connective tissue skeleton of the tumor. Collagen fibers sometimes split the parenchyma of the tumor into small tumor focuses. It should be noted that the number of connective tissue elements in the tumor is negligible, and the parenchymal elements are dominated by stromal structures by volume (Fig. 6).

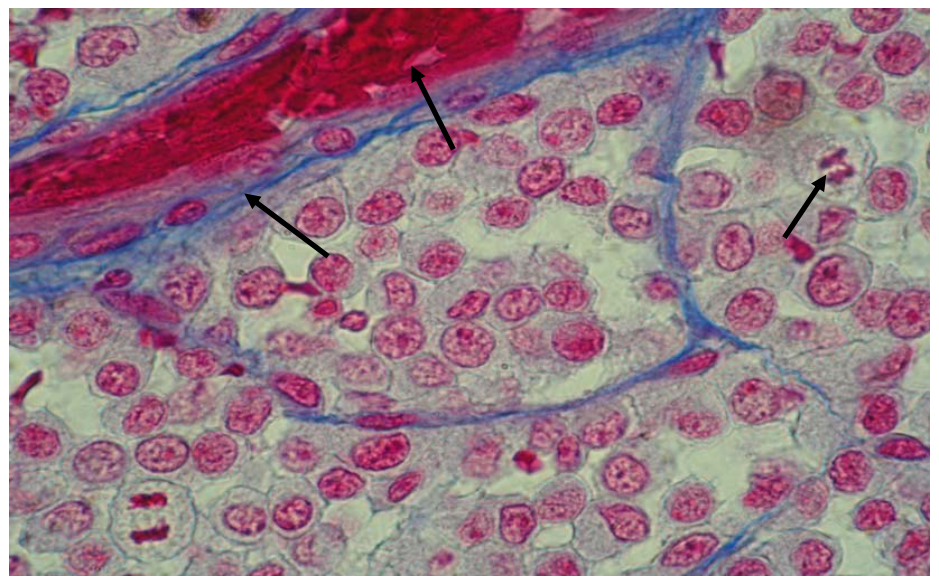

Fig. 6. The tissue of transmissible venereal sarcoma of spontaneous origin from a 2-years-old dog (staining with azan by Heydengain, amplification $\times 1000$ )

Tumor cells of round form, with a volume round or oval nucleus and a narrow cytoplasm. Sometimes mitoses are visualized. In some of the tumor cells that divide, there is a pathology of mitosis - in particular, there are chromatic bridges that connect the opposite poles of fission, resulting in a violation of the course of the final stages of cell division. 
The major glycosaminoglycans and glycogen are located in a large number around the newly formed vessels and in the placement of cell infiltrates.

In addition, in a moderate amount, PAS-positive substances are placed on the course of newly formed collagen fibers of the connective tissue stroma of the tumor.

In the stroma of the tumor and in the wall of the newly formed vessels, there is a significant number of major glycosaminoglycans, and moderate amounts of glycogen, in the form of small granules of intense red color, due to the fact that in these areas there is an intensification of synthetic processes directed at the synthesis of collagen and other components of the stromal structures. In the lumen of the vessels, segmental neutrophil granulocytes are visualized. In stroma, infiltration by lymphocytes, histiocytes, single neutrophilic granulocytes is recorded.

In the cytoplasm of tumor cells, the concentration of major glycosaminoglycans and glycogen is low. Only in some (single) parenchymal cells of the tumor there is a faint pink shade and isolated red granules, indicating the placement of the main glycosaminoglycans and single glycogen granules in these regions (Fig. 7).

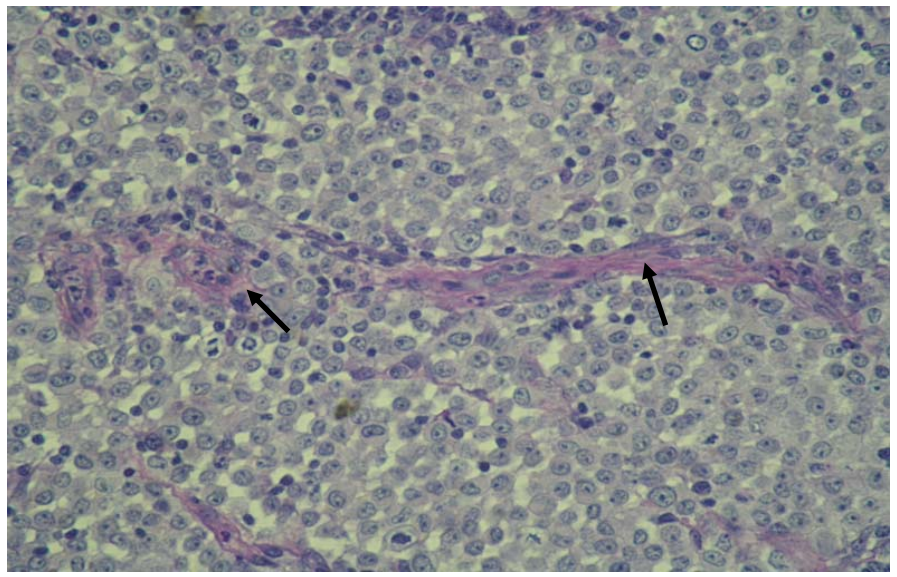

Fig. 7. The tissue of transmissible venereal sarcoma of spontaneous origin from a 2-years-old dog (McManus Schiff-reaction, amplification $\times 400$ )

The destruction of the vessel wall and the invasion of her tumor cells were not observed. A significant number of major glycosaminoglycans and moderate amounts of glycogen were recorded in the vascular wall and in the stromal regions where the synthesis of collagen fibers is observed.

The cytoplasm of the tumor cells contains a small amount of major glycosaminoglycans and glycogen (the latter can be detected only in certain tumor cells). Sometimes the inclusions of glycogen (small granules of intense red color) in the nuclei of tumor cells were visualized.

Moderate amounts of alkaline phosphatase (black-brown areas, according to the black color method) are located in the nucleus of tumor cells. In nucleoli and portions of condensed chromatin, the concentration of alkaline phosphatase is slightly higher than in other parts of the nucleoplasm. A slightly smaller amount of alkaline phosphatase is localized in the cytoplasm of the parenchymal cells of the neoplasm, which sometimes has a black-and-white coloration (Fig. 8).

The parenchyma of the tumor is positive to vimentin. In particular, there is a bright uniformly positive reaction of the cytoplasm of tumor cells to vimentin filaments. The said reaction of parenchymal cells to vimentin indicates epithelial-mesenchymal transformation of tumor cells (Fig. 9).

To detect cytokeratin in tumor cells, common cytokeratin (AE1/AE3 clones), a broad-specific antibody, was used.

A positive-local reaction to cytokeratin was observed, which may indicate the presence of micrometastases in the lymph nodes (Fig. 10). 


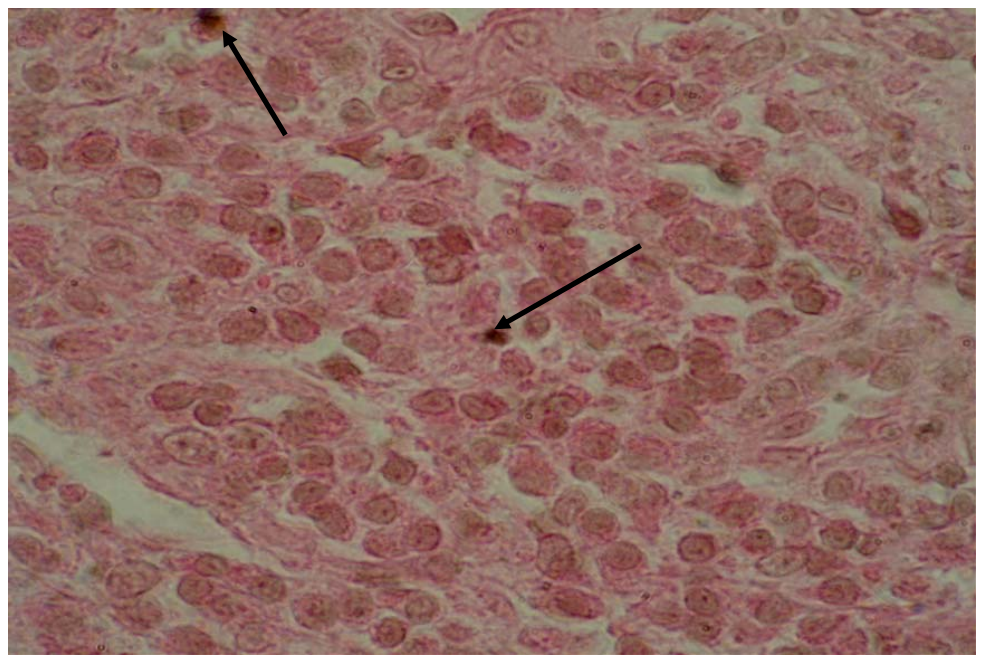

Fig. 8. The tissue of transmissible venereal sarcoma of spontaneous origin from a 1.5 -years-old $\operatorname{dog}$ (Gomori method for alkaline phosphatase, amplification $\times 1000$ )

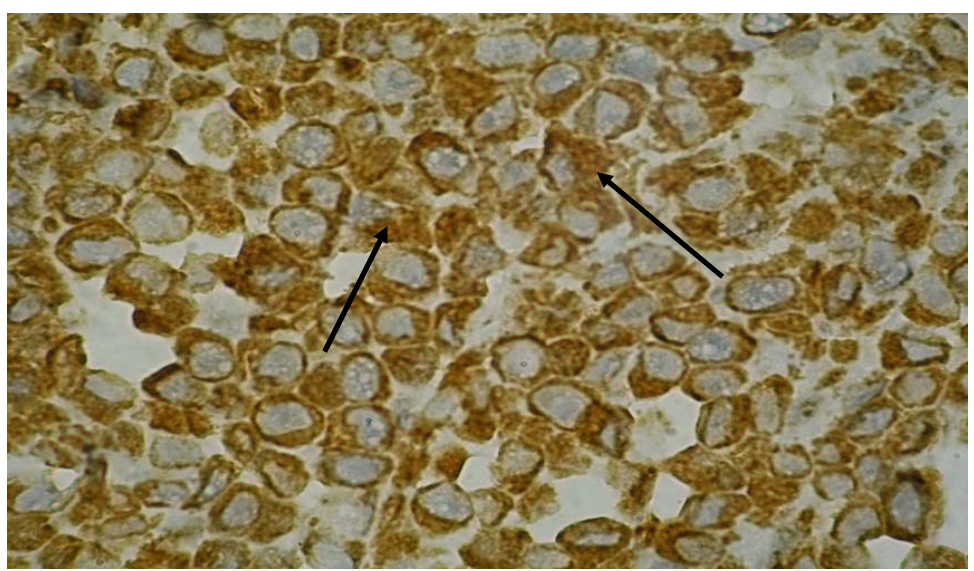

Fig. 9. The tissue of transmissible venereal sarcoma of spontaneous origin from a 4-years-old dog. Positive reaction on Vimentin (IS52730-2IR630, Monoclonal Mouse Anti- Vimentin, Clone V9), (amplification $\times 1000)$

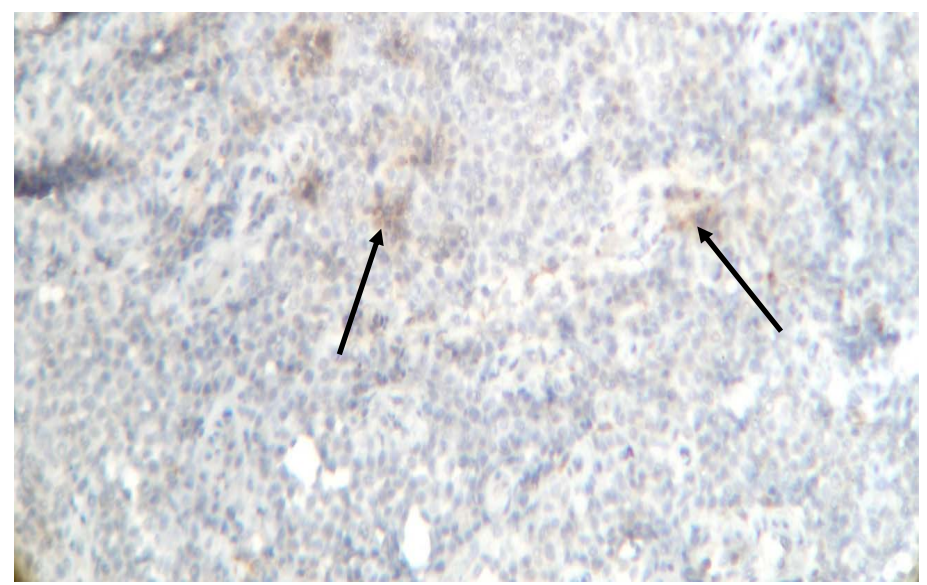

Fig. 10. The tissue of transmissible venereal sarcoma of spontaneous origin from a 2-years-old dog. Positive-local response to Cytokeratin Clone AE1/AE3 (DBS DSCE-Mob190-A, Monoclonal Mouse Antibody to Human, Clone AE1/AE3. (amplification $\times 400$ ) 
In tumor stroma existing structures that are positive for myogenine. A particularly pronounced positive reaction was recorded in the placement of stromal vessels (positive response to myogenin has the muscle elements of the vessels). Parenchymal tumor elements do not give a positive reaction to myogenin (Fig. 11).

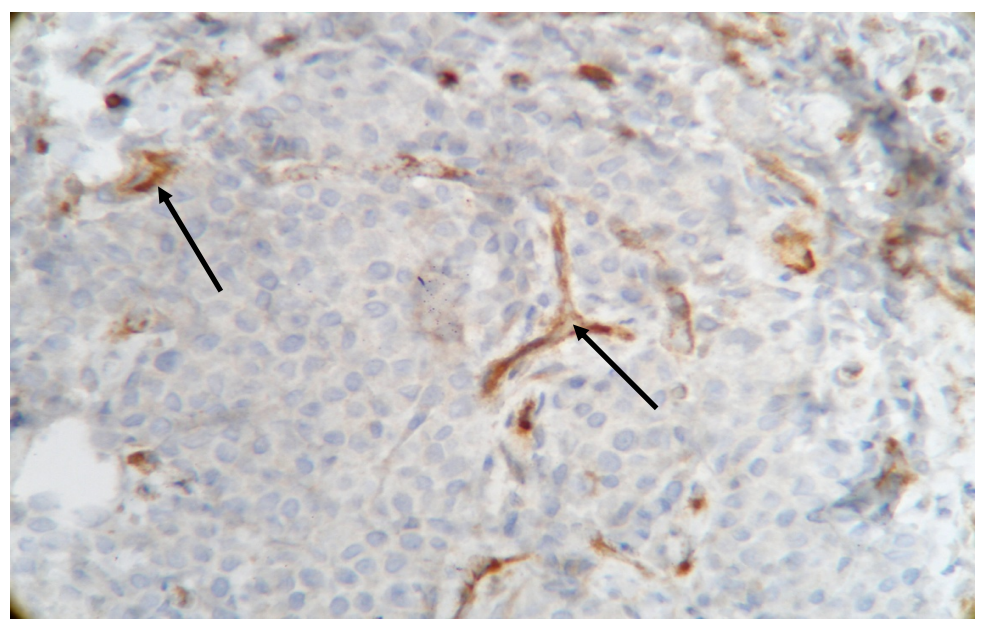

Fig. 11. The tissue of transmissible venereal sarcoma of spontaneous origin from a 3-years-old dog. Positive-local response to Myogenin (Dako IS067, Monoclonal Mouse Anti-Myogenin, Clone F5D), (amplification $\times 400)$

In our opinion, the positive-local reaction to Myogenin in the stroma of the tumor indicates a weakly developed capillary mesh.

For genital localization, tumor nodes are located in the prick of the vagina in females and preputia in males. They are characterized by expansive, papilloma-like growth. Immunohistochemical properties of tumor cells indicate that they have vimentine marker, positive local reaction to myogenin, cytokeratin and negative on CD31, CD34, S-100 protein and desmin.

\section{Discussions}

One of the problems that significantly impedes the treatment and diagnosis of animal oncological diseases is the inadequate study of the pathogenic effect of the tumor on their body and the lack of reliable methods and means for early diagnosis. The rapid development of complications, in particular, tissue necrosis, the absence of signs of inflammation for many cancer diseases, suggests that tumors have to be studied due to clinical changes in the body of animals and on hematological parameters.

Canine transmissible venereal sarcoma occurs more often than it is diagnosed, since clinical manifestations (bleeding, ulcers, changes in the anatomical structure of genital organs) occur only in the stages when the tumor has a progressive nature. The results of our research are consistent with the data $[22,23]$.

According to the results of studies, cytological and histological signs of transmissible venereal sarcoma of spontaneous origin belongs to the circular cell sarcoma of the alveolar type. Our research confirms and complements the results [24, 25].

In our opinion, and some authors [26], the changes immunohistochemical properties of tumor cells may indicate the epithelial-mesenchymal transformation and poorly developed capillar mesh.

\section{Conclusions}

1. The transmissible venereal sarcoma, according to the histological and cytological structure, belongs to the circular cell sarcoma of the alveolar type. The tumor consists predominantly of monomorphic cells that are located in the form of nests in the center of which there are cavities resembling lung alveoli. 
2. For genital localization, the primary tumor nodes are located in the subepithelial layer of prickly vagina in females and preputia in males. They are characterized by expansive, papilloma-like growth.

3. The outer surface of the tumor nodes is covered with a multilayered flat epithelium with a typical basement membrane. The tumor is represented by a fibrous connective tissue in which the blood vessels of the capillary type are present.

4. With microscopy in the early stages of growth, transmissible venereal sarcoma looks like a lumpy cell that captures the dermis and subcutaneous soft tissues.

5. Detection of intermediate phylums in tumor cells with the help of specific antibodies allows to determine the epithelial, mesenchymal or neuroectodermal origin of tumor cells, to diagnose and to provide effective treatment. Therefore, now immunohistochemical methods of research are an integral part in the diagnosis of soft tissue sarcoma.

\section{References}

[1] Artamonov, I. A., Kleimenova, N. V. (2013). Pathomorphology transmissible venereal sarcoma. Network scientific journal OGAU, 1, 45-47.

[2] Marcos, R., Santos, M., Marrinhas, C., Rocha, E. (2006). Cutaneous transmissible venereal tumor without genital involvement in a prepubertal female dog. Veterinary Clinical Pathology, 35 (1), 106-109. doi: 10.1111/j.1939-165x.2006.tb00097.x

[3] Stimmelmayr, R. (2010). Transmissible venereal tumor: a special canine case of contagious cancer cells. Vet Times, 14-19.

[4] Miller, F. P., Vandome, A. F., McBrewster, J. (2010). Canine transmissible venereal tumor. Alphascript Publishing, 84.

[5] Murchison, E. P., Wedge, D. C., Alexandrov, L. B., Fu, B., Martincorena, I., Ning, Z. et. al. (2014). Transmissible Dog Cancer Genome Reveals the Origin and History of an Ancient Cell Lineage. Science, 343 (6169), 437-440. doi: 10.1126/science.1247167

[6] VonHoldt, B. M., Ostrander, E. A. (2006). The Singular History of a Canine Transmissible Tumor. Cell, 126 (3), 445-447. doi: 10.1016/j.cell.2006.07.016

[7] Abuom, T. O., Mande, J. D. (2007). Transmissible Venereal Tumor with Subcutaneous and Bone Metastasis in a Dog. Kenya Veterinarian, 30 (1), 11-13. doi: 10.4314/kenvet.v30i1.39617

[8] Henson, K. L. (2001). Reproductive system. Atlas of canine and feline cytology. Philadelphia: WB Saunders Co, 296-297.

[9] MacEwen, G. (2001). Transmissible venereal tumor. Small animal clinical oncology. Philadelphia: WB Saunders Co, 651-655.

[10] Ferreira, A. J. A., Jaggy, A., Varejao, A. P., Ferreira, M. L. P., Correia, J. M. J., Mullas, J. M. et. al. (2000). Brain and ocular metastases from a transmissible venereal tumour in a dog. Journal of Small Animal Practice, 41 (4), 165-168. doi: 10.1111/j.1748-5827.2000.tb03187.x

[11] Rebbeck, C. A., Thomas, R., Breen, M., Leroi, A. M., Burt, A. (2009). Origins And Evolution Of A Transmissible Cancer. Evolution, 63 (9), 2340-2349. doi: 10.1111/j.1558-5646.2009.00724.x

[12] Murchison, E. P., Wedge, D. C., Alexandrov, L. B., Fu, B., Martincorena, I., Ning, Z. et. al. (2014). Transmissible Dog Cancer Genome Reveals the Origin and History of an Ancient Cell Lineage. Science, 343 (6169), 437-440. doi: 10.1126/science.1247167

[13] Purohit, G. N. (2009). Canine transmissible venereal tumor: a review. The Internet Journal of Veterinary Medicine, 6 (1). doi: 10.5580/a6a

[14] Eze, C. A., Anyanwu, H. C., Kene, R. (2008). Review Of Canine Transmissible Venereal Tumour (TVT) In Dogs. Nigerian Veterinary Journal, 28 (1), 54-70. doi: 10.4314/nvj.v28i1.3544

[15] Utpal, D., Kumar, D. (2000). Review of canine transmissible venereal sarcoma. Veterinary Research Communications, 24 (8), 545-556. doi: 10.1023/a:1006491918910

[16] Rogers, K. S. (1997). Trasmissible venereal tumor in the dog. Compendium on Continuing Education for the Practising Veterinarian, 19 (9), 1036-1045.

[17] Bespalova, T. Y. (2011). Cytological and hematological changes in small animals with cancer. Samara, 21-29. 
[18] Das, A. K., Das, U., Das, D., Sengupta, J. (1990). Histopathological study of canine transmisible venereal tumor. The Indian Veterinary Journal, 67, 473-475.

[19] Zinkl, J. G. (1999). Cytology of the male reproductive tract. Diagnostic cytology and hematology of the dog and cat. St. Louis: Mosby Inc, 236-237.

[20] Kovaleva, N. V., Dansarynova, O. S. (2014). Wound microflora in the affected areas transmissible venereal sarcoma of dogs. Bulletin Of The Council Krasnodar, 9, 161-163.

[21] Marchal, T., Chabanne, L., Kaplanski, C., Rigal, D., Magnol, J. P. (1997). Immunophenotype of the canine transmissible venereal tumour. Veterinary Immunology and Immunopathology, 57 (1-2), 1-11. doi: 10.1016/s0165-2427(96)05757-1

[22] Artamonov, I. A., Kleimenova, N. V. (2013) Pathomorphology transmissible venereal sarcoma. Network scientific journal OGAU, 1, 45-47.

[23] Rogers, K. S. (1997) Trasmissible venereal tumor in the dog. Comp. Contin. Educ. Pract. Vet., 19 (9), 1036-1045.

[24] Stimmelmayr, R. (2010) Transmissible venereal tumor: a special canine case of contagious cancer cells. Vet Times, 14-19.

[25] Canine Transmissible Venereal Tumor: A Review. (2009). The Internet Journal of Veterinary Medicine, 6 (1). doi: 10.5580/a6a

[26] Rebbeck, C. A., Thomas, R., Breen, M., Leroi, A. M., Burt, A. (2009). Origins and evolution of a transmissible cancer. Evolution, 63 (9), 2340-2349. doi: 10.1111/j.1558-5646.2009.00724.x 